\title{
Transfusion-Transmissible Infections among Voluntary Blood Donors at Wolaita Sodo University Teaching Referral Hospital, South Ethiopia
}

\author{
Fithamlak Solomon Bisetegen, ${ }^{1}$ Fanuel Belayneh Bekele, ${ }^{2}$ \\ Temesgen Anjulo Ageru, ${ }^{3}$ and Fiseha Wadilo Wada ${ }^{4}$ \\ ${ }^{1}$ School of Medicine, College of Health Sciences, Wolaita Sodo University, P.O. Box 138, Wolaita Sodo, Ethiopia \\ ${ }^{2}$ School of Public Health and Environmental Science, College of Health Sciences and Medicine, \\ Hawassa University, Hawassa, Ethiopia \\ ${ }^{3}$ Wolaita Sodo University Teaching Referral Hospital Laboratory, P.O. Box 378, Wolaita Sodo, Ethiopia \\ ${ }^{4}$ School of Medicine, College of Health Sciences and Medicine, Wolaita Sodo University, P.O. Box 138, \\ Wolaita Sodo, Ethiopia
}

Correspondence should be addressed to Fithamlak Solomon Bisetegen; fitha2007@yahoo.com

Received 24 February 2016; Revised 5 July 2016; Accepted 14 July 2016

Academic Editor: Elisabetta Caselli

Copyright (C) 2016 Fithamlak Solomon Bisetegen et al. This is an open access article distributed under the Creative Commons Attribution License, which permits unrestricted use, distribution, and reproduction in any medium, provided the original work is properly cited.

\begin{abstract}
Background. Transfusion-transmissible infections, human immunodeficiency virus, hepatitis $B$ virus, hepatitis $C$ virus, and syphilis are among the greatest threats to blood safety and pose a serious public health problem. Objective. To determine the magnitude of blood borne infections among blood donors at Wolaita Sodo University Teaching Referral Hospital. Methods and Materials. A crosssectional study was conducted from 10/11/2015 up to 10/12/2015. 390 donors were consecutively included and data on donor's age, sex, blood type, and serum screening results were obtained by structured questionnaire and laboratory investigation. The collected data were entered into Epi Data version 1.4 and then exported to SPSS version 20.0 for analysis. Result. The seroprevalence of blood borne pathogens is $29.5 \%$ of which HCV, HBV, HIV, and syphilis account for $8.5 \%, 9.5 \%, 6.4 \%$, and 7.5\%, respectively. Multiple infections were observed among $2.8 \%$ of the infected individuals. In addition, age $\geq 30$ has a significant association with HCV. Conclusion. Significantly higher prevalence of transfusion-transmissible infections was identified from blood donors and they remain to be the greatest threat to blood safety, so comprehensive screening of donors' blood for HIV, HBV, HCV, and syphilis using standard methods is highly recommended to ensure the safety of blood recipient.
\end{abstract}

\section{Introduction}

Although blood transfusion is one of the known therapeutic interventions that cut across a number of clinical disciplines, the practice is not without risks [1]. The highest risk groups are children suffering from malaria and anemia; women with pregnancy related hemorrhage; and victims of major trauma [2].

Transfusion-transmissible infectious agents such as human immunodeficiency virus (HIV), hepatitis B virus (HBV), hepatitis $\mathrm{C}$ virus (HCV), and syphilis are among the greatest threats to blood safety for the recipient and pose a serious public health problem [3].

Among HIV transmission ways blood transfusion accounts for $5-10 \%$ in Sub-Saharan Africa [4]. Similarly, $12.5 \%$ of patients who received blood transfusion are at risk of posttransfusion hepatitis [5].

The high prevalence of HIV, HBV, HCV, and syphilis has heightened the problems of blood safety in Ethiopia. Thus, continuous monitoring of the magnitude of transfusiontransmissible infections in blood donors is important for estimating the risk of transfusion and optimizing donor 
recruitment strategies to minimize infectious diseases transmission [3].

However, there is scarce published information about the burden of major transfusion-transmissible infections in the study area.

Morbidity and mortality resulting from the transfusion of infected blood have far-reaching consequences, not only for the recipients themselves, but also for their families, their communities, and the wider society $[6,7]$.

Only continuous improvement and implementation of donor selection, sensitive screening tests, and effective inactivation procedures can ensure the elimination, or at least reduction, of the risk of acquiring TTIs [8].

Evaluation of data on the prevalence of transfusiontransmissible infections, namely, HIV, HBV, HCV, and syphilis, among blood and plasma donors permits an assessment of the occurrence of infections in the blood donor population and consequently the safety of the collected donations. It also gives an idea of the prevalence of the transfusiontransmissible infections (TTIs) among blood donors which allows for assessment of epidemiology of these infections in the community.

\section{Methods and Materials}

2.1. Study Area and Setting. Institution based cross-sectional study was conducted at Wolaita Sodo University Teaching Referral Hospital from 10/11/2015 up to $10 / 12 / 2015$. The university hospital provides clinical services for 85,700 populations. In 2015, approximately 1,500 units of blood were transfused in the hospital.

2.2. Study Population. Three hundred ninety blood donors were prospectively recruited in the study from October 10, 2015, up to November 10, 2015, and convenient sampling techniques were used to recruit blood donors who were eligible to donation, consented, interviewed, and gave blood for serum screening of transfusion-transmissible infections.

All blood donors who fulfilled the national and regional blood bank criteria were included. Blood donors who did not meet the inclusion criteria ( $<18$ years, $>65$ years, history of long-term medication use, and unwillingness to give oral informed consent) were excluded from the study.

2.3. Data Collection. Data on blood donor's age, sex, blood group, serological results of $\mathrm{HCV}, \mathrm{HBs} \mathrm{Ag}, \mathrm{HIV}$, and syphilis were collected at the time of blood collection, by using a structured questionnaire. The laboratory uses immune chromatographic techniques to screen blood donors. In addition, the blood samples were retested with ELISA technique to confirm the results.

2.4. Laboratory Testing. Five milliliters of venous blood was collected using sterile test tube from each blood donor. Serum was separated by centrifugation at a speed of 3500 revolutions per minute (rpm) for 5 minutes and $2 \mathrm{~mL}$ of serum was collected from each sample using sterile plastic vials. Blood group for each blood donor was determined at each study area using blood group antisera: anti-A, anti-B, and anti-D for $\mathrm{Rh}$ factor. Each donor was tested for HBs Ag and anti-HCV by ACON one-step insert rapid test strips in the laboratory. To confirm the results, samples were retested by using 4thgeneration ELISA technique. Blood samples tested by using serological assays for HIV infection were screened by 4thgeneration ELISA, Vironostika HIV Uni-Form II AG/Ab. Hepatitis B virus was screened by using an immunoassay ELISA Hepanostika HBs Ag Uni-Form II, hepatitis C virus by using the human anti-HCV 3rd-generation ELISA, and syphilis by using syphilis antibody ELISA (FTA).

2.5. Data Management. The collected data were entered into Epi Data version 1.4 and then exported to SPSS version 20 for analysis. Summary statistics such as frequencies and percentages were computed. The results were presented using tables, charts, and graphs. Chi-square was used to see a difference of blood borne pathogens between age, sex, and blood groups. A $p$ value of $<0.05$ was considered as a significant difference.

2.6. Quality Assurance. All positive samples and $10 \%$ negative samples were retested in South Nations and Nationalities People Region/SNNPR/regional laboratory to ensure the quality. Standard operational procedures were strictly followed and QC materials were used for all serological tests. In addition, laboratory quality was assured by well-trained professionals, training, and supervision during sample collection.

2.7. Ethical Consideration. The study was carried out after getting approval from the ethical clearance committee of Wolaita Sodo University. Consent was signed before sample collection and the participants' information is used only for study purpose. Respondents were not identified by name and the participant had the right to discontinue the participation any time.

\section{Result}

3.1. Donor's Characteristics. A total of 390 blood donors were included during the study period; among these, 291 (74.6\%) were male and 99 (25.4\%) were female with female to male ratio of $1: 3$. The median age of the donors was 28 years with the range 18 and 60 years.

Regarding donors ABO blood group distribution, 200 $(51.3 \%)$ of the donors were "O" blood type. The remaining $104(26.7 \%), 76(19.7 \%)$, and $9(2.4 \%)$ of the participants were "A," "B," and "AB" blood types, respectively.

3.2. Prevalence of Blood Borne Pathogens. Blood borne pathogens were detected among 115 (29.5\%) of the donors and $275(70.5 \%)$ were free from the four infections. Donors with positive results for $\mathrm{HCV}$ and $\mathrm{HBs}$ Ag were 33 (8.5\%) and 37 (9.5\%), respectively. Twenty-five of them were positive for HIV whereas 31 (7.9\%) were positive for syphilis test (Figure 1).

Among those who have the infection, 104 (26.7\%) were positive for only one of the pathogens and the other $11(2.8 \%)$ 


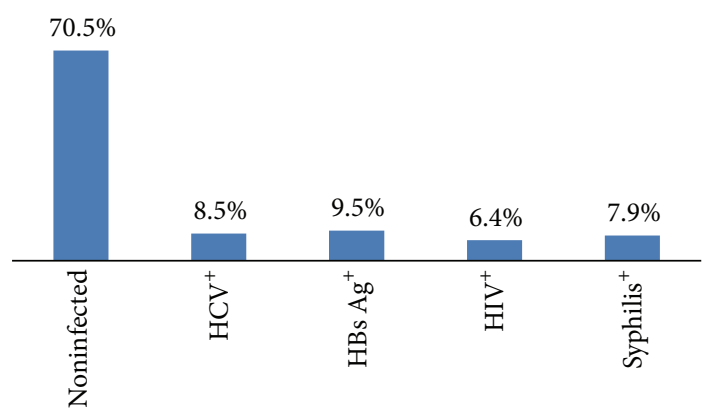

FIGURE 1: Distribution of blood borne pathogens infection among blood donors at Wolaita Sodo Teaching Referral Hospital 2015.

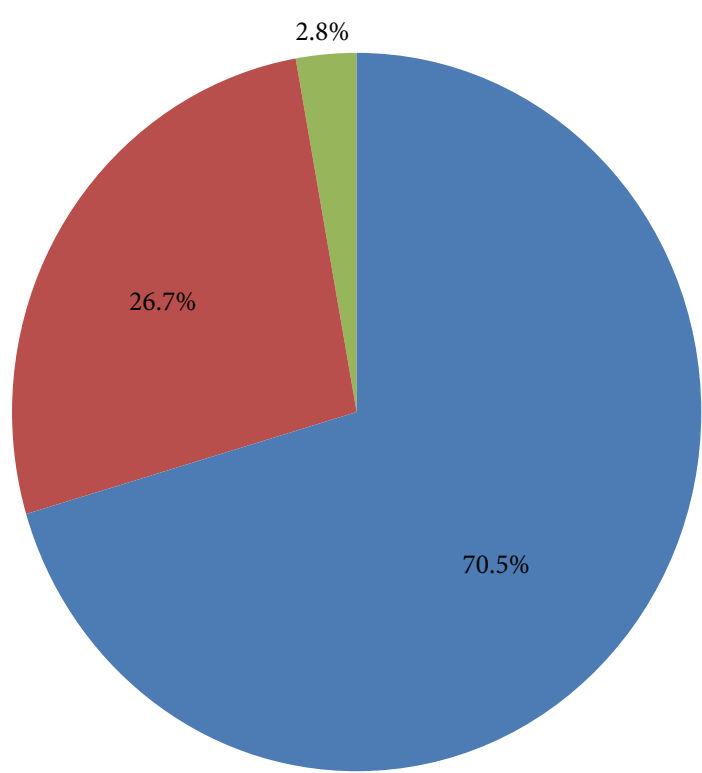

No infection

Infected with one pathogen

Infected with two pathogens

FIGURE 2: Infection status of blood donors by blood borne pathogens at Wolaita Sodo Teaching Referral Hospital 2015.

were coinfected with two of the four blood borne infections. Coinfection for more than two pathogens was not detected. Five of the coinfected donors were positive for HBs Ag and syphilis antibody tests. In addition, two donors with HIV positive screening result were also positive for HCV antibody test and other two were positive for syphilis antibody test (Figure 2).

Almost one-third of all male and 29 (29.3\%) of all female donors in this study were positive at least for one of the four blood borne pathogens. Prevalence of HCV infection was $8.9 \%$ among males and 7.1\% among female donors. Donors who are positive for HBs Ag test were $11.0 \%$ in males and $5.1 \%$ in females. About seven percent of the male donors and five percent of the female donors have been positive for HIV. Antibody evidence for Treponema pallidum was detected among $6.2 \%$ of male and $13.1 \%$ of female donors.
Regarding infection distribution with age categories, 65 (23.6\%) of donors less than or equal to 30 years and 50 (43.9\%) of donors greater than 30 years have evidence of at least one blood borne pathogen. The predominant positive result was for HBs Ag, which accounts for 24 (8.7\%) and 13 (11.4\%) among donors less than or equal to 30 years of age and greater than 30 years, respectively. Sex has no significant association with any of transfusion-transmissible infections but age $\geq 30$ years has a significant association with $\mathrm{HCV}$ prevalence $(p=0.04)$ (Table 1$)$.

Regarding the distribution of the infections with blood group, 8 (10.4\%) of donors with A blood group are positive for $\mathrm{HCV}$, whereas 10 (13\%) of $\mathrm{HBs} \mathrm{Ag}$ reactive donors were $\mathrm{B}$ blood group. Among A blood group donors, 17 (8.5\%) were positive for HIV, and 10 (9.6\%) were reactive for syphilis. $\mathrm{RH}^{+}$donors showed that positive reaction for HCV accounts for $8.2 \%$ and $9.6 \%$ positive for $\mathrm{HBs} \mathrm{Ag}$. $\mathrm{RH}^{-}$donors showed relatively high prevalence of HCV, 4 (11.8\%), and syphilis, 5 (14.7\%) (Table 2).

\section{Discussion}

In the current study, the seroprevalence of transfusiontransmissible infections was 115 (29.5\%) which is similar to 29.85\% reported in Burkina Faso [9], 21.6\% in Cameroon [10], and $19.3 \%$ in Nigeria [11]. But the result is lower than $43.2 \%$ reported in Bahir Dar, Ethiopia [2], which could be due to the fact that most of the study participants in the previous study were commercial blood donors whereas only voluntary donors were included in this study. The current finding is much higher than previous studies conducted elsewhere, 14\% in Islamabad [12], 9.6\% in Sudan [13], 2.6\% in Northeast Ethiopia, Gondar [3], 2.22\% in Karnataka, India [14], 1.7\% in Nepal [15], and $1.1 \%, 1 \%$, and $0.93 \%$ in India [16-18]. Hence, even when compared with other resource constrained settings, the burden of blood borne pathogens is quite high in this study. Widest difference in blood borne pathogen in different studies in our country and others could be due to the use of different generation of ELISA test kits having different sensitivities and specificities and geographical factors.

Donors with positive results for HCV, $33(8.5 \%)$ in this study, are comparable with $13.3 \%$ reported in Bahir Dar, North Ethiopia [2], 8.7\% in Burkina Faso [9], 8.34\% in Islamabad [12], and $8 \%$ in Ghana [19]. But the result is considerably higher than studies conducted elsewhere, $4.8 \%$ [10], 3.4\% [13], $1.7 \%$ [20], $1.1 \%$ [21], $0.51 \%$ [22], $0.48 \%$ [23], $0.21 \%$ [24], $0.2 \%$ [17], 0.16\% [25], and $0.03 \%$ [14]. The higher prevalence of this study as compared with the above findings could be supported by the reason that most of the donations before six years were commercial donors and they were donating blood without being screened for HCV and these strains may be circulating in the community without noticing.

Prevalence of HBs Ag among blood donors in this study, $9.5 \%$, is lower than a prevalence of $25 \%$ in North Ethiopia [2], 14.9\% in Burkina Faso [9], and $14.3 \%$ in Jos, Nigeria [26]. But it is in harmony with a prevalence of $10.1 \%$, reported the Cameroon study [10]. On the contrary, the current finding is in discordance with studies conducted in 
TABLE 1: Distribution of blood borne pathogens by sex and age among blood donors at Wolaita Sodo Teaching Referral Hospital, 2015.

\begin{tabular}{|c|c|c|c|c|c|c|c|c|}
\hline \multirow{3}{*}{ Variable } & \multicolumn{2}{|c|}{$\mathrm{HCV}$} & \multicolumn{2}{|c|}{ HBs Ag } & \multicolumn{2}{|c|}{ HIV } & \multicolumn{2}{|c|}{ Syphilis } \\
\hline & $\mathrm{R}$ & NR & $\mathrm{R}$ & NR & $\mathrm{R}$ & NR & $\mathrm{R}$ & NR \\
\hline & No (\%) & No (\%) & No (\%) & No (\%) & No (\%) & No (\%) & No (\%) & No (\%) \\
\hline \multicolumn{9}{|l|}{ Sex } \\
\hline Male & $26(8.9)$ & 265 (91.1) & $32(11.0)$ & $259(89.0)$ & $20(6.9)$ & $271(93.1)$ & $18(6.2)$ & $273(93.8)$ \\
\hline Female & $7(7.1)$ & $92(92.9)$ & $5(5.1)$ & $94(94.9)$ & $5(5.1)$ & $94(94.9)$ & $13(13.1)$ & $86(86.9)$ \\
\hline \multicolumn{9}{|c|}{ Age category } \\
\hline$\leq 30$ & $22(8.0)$ & $254(92.0)$ & $24(8.7)$ & $252(91.3)$ & $11(4.0)$ & $265(96.0)$ & $13(4.7)$ & $263(95.3)$ \\
\hline$>30$ & $11(9.6)$ & $103(90.4)$ & $13(11.4)$ & $101(88.6)$ & $14(12.3)$ & $100(87.7)$ & $18(15.8)$ & $96(84.2)$ \\
\hline
\end{tabular}

TABLE 2: Distribution of blood borne pathogens by donor's blood type among blood donors at Wolaita Sodo Teaching Referral Hospital, 2015.

\begin{tabular}{|c|c|c|c|c|c|c|c|c|}
\hline \multirow{3}{*}{ Blood type } & \multicolumn{2}{|c|}{$\mathrm{HCV}$} & \multicolumn{2}{|c|}{$\mathrm{HBs} \mathrm{Ag}$} & \multicolumn{2}{|c|}{ HIV } & \multicolumn{2}{|c|}{ Syphilis } \\
\hline & $\mathrm{R}$ & NR & $\mathrm{R}$ & NR & $\mathrm{R}$ & NR & $\mathrm{R}$ & NR \\
\hline & No $(\%)$ & No (\%) & No (\%) & No (\%) & No (\%) & No (\%) & No (\%) & No (\%) \\
\hline \multicolumn{9}{|c|}{ ABO blood group } \\
\hline $\mathrm{A}^{+/-}$ & $5(4.8)$ & $99(95.2)$ & $7(6.7)$ & $97(93.3)$ & $5(4.8)$ & $99(95.2)$ & $10(9.6)$ & $94(90.4)$ \\
\hline $\mathrm{B}^{+/-}$ & $8(10.4)$ & $69(89.6)$ & $10(13.0)$ & $67(87.0)$ & $2(2.6)$ & $75(97.4)$ & $6(7.8)$ & $71(92.2)$ \\
\hline $\mathrm{AB}^{+/-}$ & $1(1.1)$ & $8(98.9)$ & $2(2.2)$ & $7(97.8)$ & $1(1.1)$ & $8(98.9)$ & $1(1.1)$ & $8(98.9)$ \\
\hline $\mathrm{O}^{+/-}$ & $19(9.5)$ & $181(90.5)$ & $18(9.0)$ & $182(91.0)$ & $17(8.5)$ & $183(91.5)$ & $14(7.0)$ & $186(93.0)$ \\
\hline \multicolumn{9}{|c|}{ RH blood group } \\
\hline Positive & $29(8.2)$ & $326(91.8)$ & $34(9.6)$ & $321(90.4)$ & $24(6.8)$ & $332(93.2)$ & $26(7.3)$ & $329(92.7)$ \\
\hline Negative & $4(11.8)$ & $30(88.2)$ & $3(8.8)$ & $31(91.2)$ & $1(2.9)$ & $33(97.1)$ & $5(14.7)$ & $29(85.3)$ \\
\hline
\end{tabular}

Ethiopia and elsewhere, 6.2\% in Northwest Ethiopia [20], $5.3 \%$ in Nigeria [21], 5\% in Sudan [13], 4.7\% in Gondar [20], 3.91\% in Islamabad [12], $1.16 \%$ in China [22], $0.9 \%$ [18], $0.63 \%$ [17], $0.49 \%$ [24], and $0.3 \%$ [25] in India, and $0.09 \%$ [23] in Canada. These variations could also be due to actual changes in population risks or effectiveness of donor screening measures.

HIV prevalence of $6.4 \%$ observed among blood donors at Wolaita Sodo University Teaching Referral Hospital is lower than $11.7 \%$ for Bahir Dar, Ethiopia [2], but considerably comparable with $4.1 \%$ reported in Cameroon [10] and 3.8\% reported in Ghana [19] but higher than previous studies conducted in the country and elsewhere $[12,13,17,18,21-$ $23,25,27,28]$ in different countries. HIV prevalence in the current study shows high discrepancy with the nationwide adult HIV prevalence estimate of $1.1 \%$ [29], but lower than $10.2 \%$ reported in SNNPR [30]. The high prevalence of HIV seropositivity in comparison with the national figure and other local regions could be due to lower voluntary counseling test coverage in this region than the other [30].

Treponemal positivity prevalence of $7.9 \%$ in our study is lower than the prevalence of $13.5 \%$ reported in Ghana [19], but in harmony with $7.5 \%$ prevalence reported in similar study conducted in the same country, Ghana [31], and 5.7\% in Cameroon [10]. Our finding is higher than 3.96\% prevalence in Burkina Faso [9], 1.2\% in Bahir Dar [2], 0.89\% in Islamabad [12], $0.3 \%$ in China [22], $0.23 \%$ in India [28], 0.22\% in Gujrat, India, and Uttarakhand, India $[17,18]$. This could possibly be explained in association with the higher prevalence of HIV in this study where one could facilitate the transmission of the others.

In the current study, there was no association between sex, ABO blood group, $\mathrm{RH}$ factor, and any of blood borne pathogens. Age group $\geq 30$ have a significant association with $\mathrm{HCV}$ which is unclear but could be explained by the fact that liver fibrosis increases with old age and in age groups 40-64 and could also be due to the highest seropositivity of HCV for individuals aged $>30[32,33]$.

\section{Conclusion and Recommendation}

In general, the prevalence of transfusion-transmissible infection is high in the study area. The blood donors in this study were voluntary subjects, who are apparently healthy, but this study found that these diseases are prevalent among volunteer donors. Thus, strict selections of blood donors with standard methods are highly recommended to ensure the safety of blood for the recipient.

\section{Competing Interests}

All authors declare that they have no competing interests.

\section{Authors' Contributions}

Fithamlak Solomon Bisetegen conceived the study, Fithamlak Solomon Bisetegen, Fanuel Belayneh Bekele, Temesgen 
Anjulo Ageru, and Fiseha Wadilo Wada participated in the design of the study and performed the statistical analysis, and Fithamlak Solomon Bisetegen and Fanuel Belayneh Bekele interpreted the data. Fithamlak Solomon Bisetegen obtained ethical clearance and permission for study. Temesgen Anjulo Ageru supervised data collectors; Fithamlak Solomon Bisetegen, Fanuel Belayneh Bekele, Temesgen Anjulo Ageru, and Fiseha Wadilo Wada drafted the paper or revisited it critically for important intellectual content. All authors read and approved the final paper.

\section{Acknowledgments}

The authors acknowledge all the staff members of blood bank unit, Wolaita Sodo University, Ethical Review Board for the ethical clearance, and blood donors.

\section{References}

[1] A. F. Fleming, "HIV and blood transfusion in sub-Saharan Africa," Transfusion Science, vol. 18, no. 2, pp. 167-179, 1997.

[2] D. Azene, A. Bayeh, and W. Fisseha, "Seroprevalence of major blood-borne infections among blood donors at Felege Hiwot referral hospital, Northwest Ethiopia," The Ethiopian Journal of Health Development, vol. 21, pp. 68-69, 2007.

[3] B. Tessema, G. Yismaw, A. Kassu et al., "Seroprevalence of HIV, HBV, HCV and syphilis infections among blood donors at Gondar University Teaching Hospital, Northwest Ethiopia: declining trends over a period of five years," BMC Infectious Diseases, vol. 10, article 111, pp. 1-7, 2010.

[4] UNAIDS, Report on the Global AIDS Epidemic, Joint United Nations Program on HIV/AIDS, Geneva, Switzerland, 2002.

[5] F. A. Fasola and I. A. Otegbayo, "Post-transfusion viral hepatitis in sickle cell anaemia: retrospective-prospective analysis," Nigerian Journal of Clinical Practice, vol. 5, no. 1, pp. 16-19, 2002.

[6] World Health Organization (WHO), "Blood safety strategy for the African Region,” Tech. Rep. WHO AFR /RC51/9 Rev.1, World Health Organization, Regional Office for Africa, Brazzaville, Congo, 2002.

[7] World Health Organization (WHO), Status of Blood Safety in the WHO African Region: Report of the 2004 Survey WHO Regional Office for Africa, World Health Organization (WHO), Brazzaville, Congo, 2004.

[8] B. R. Tiwari, P. Ghimire, S. Karki, and M. Rajkarnikar, "Seroprevalence of human immunodeficiency virus in Nepalese blood donors: a study from three regional blood transfusion services," Asian Journal of Transfusion Science, vol. 2, no. 2, pp. 66-68, 2008.

[9] M. B. Nagalo, M. Sanou, C. Bisseye et al., "Seroprevalence of human immunodeficiency virus, hepatitis $B$ and $C$ viruses and syphilis among blood donors in Koudougou (Burkina Faso) in 2009," Blood Transfusion, vol. 9, no. 4, pp. 419-424, 2011.

[10] J. J. N. Noubiap, W. Y. A. Joko, J. R. N. Nansseu, U. G. Tene, and C. Siaka, "Sero-epidemiology of human immunodeficiency virus, hepatitis $B$ and $C$ viruses, and syphilis infections among first-time blood donors in Edéa, Cameroon," International Journal of Infectious Diseases, vol. 17, no. 10, pp. e832-e837, 2013.

[11] E. Nwankwo, I. Momodu, I. Umar, B. Musa, and S. Adeleke, "Seroprevalence of major blood-borne infections among blood donors in Kano, Nigeria," Turkish Journal of Medical Sciences, vol. 42, no. 2, pp. 337-341, 2012.
[12] W. Usman, K. Haroon, S. S. Humayoon, A. A. Muhammad, A. M. Muhammad, and H. A. Zahee, "Prevalence of transfusiontransmitted infections among blood donors of a teaching hospital in Islamabad, Pakistan," Pakistan Institute of Medical Sciences, vol. 8, no. 1, pp. 236-239, 2012.

[13] A. B. Elsharif, M. A. Moataz, B. H. Hamza, S. M. Omer, S. M. Mutasim, and E. H. Bader, "Sero-prevalence of viral transfusion-transmissible infections among blood donors at Kosti Teaching Hospital, White Nile State/Sudan," International Journal of Current Microbiology and Applied Sciences, vol. 4, no. 5, pp. 1132-1138, 2015.

[14] B. Bommanahalli, R. Javali, C. M. Mallikarjuna Swamy, K. Gouda, K. Siddartha, and K. P. Shashikala, "Seroprevalence of hepatitis B and hepatitis $\mathrm{C}$ viral infections among blood donors of Central Karnataka, India," International Journal of Medical Science and Public Health, vol. 3, no. 2, pp. 272-275, 2014.

[15] A. C. Shrestha, P. Ghimre, B. R. Tiwari, and M. Rajkarnikar, "Transfusion-transmissible infections among blood donors in Kathmandu, Nepal," Journal of Infection in Developing Countries, vol. 3, no. 10, pp. 794-797, 2009.

[16] A. Vinit, B. Geetha, and V. Sridevi, "Prevalence of HIV, HCV \& HBV in blood donors among the population of bhadravathi taluk, Karnataka, India," International Journal of Pharmaceutical, Chemical and Biological Sciences, vol. 5, no. 1, pp. 126-128, 2015.

[17] S. Bhawna, K. Satish, K. S. Butola, J. P. Mishra, and K. Yogesh, "Seroprevalence pattern among blood donors in a tertiary health care center," Internet Journal of Medical Update, vol. 9, pp. 10-15, 2014.

[18] G. A. Dhruva, A. H. Agravat, J. D. Dalsania, A. A. Katara, and R. G. Dave, "Transfusion transmitted diseases/infections among blood donors in a Tertiary Care Hospital at Rajkot, Gujrat, India," International Journal of Research in Medical Sciences, vol. 2, no. 4, pp. 16-19, 2014.

[19] W. Ampofo, N. Nii-Trebi, J. Ansah et al., "Prevalence of bloodborne infectious diseases in blood donors in Ghana," Journal of Clinical Microbiology, vol. 40, no. 9, pp. 3523-3525, 2002.

[20] B. Gelaw and Y. Mengistu, "The prevalence of HBV, HCV and malaria parasites among blood donors in Amhara and Tigray regional states," The Ethiopian Journal of Health Development, vol. 22, no. 1, pp. 3-7, 2007.

[21] N. A. Martina, O. G. Okorie, O. A. Ejike et al., "Seroprevalence of Human Immunodeficiency Virus (HIV), Hepatitis B Surface Antigen (HBsAg) and Hepatitis C Virus (HCV) among voluntary blood donors in Enugu Metropolis," International Journal of Medicine and Medical Sciences, vol. 5, pp. 183-187, 2015.

[22] Z.-H. Ji, C.-Y. Li, Y.-G. Lv et al., "The prevalence and trends of transfusion-transmissible infectious pathogens among firsttime, voluntary blood donors in Xi'an, China between 1999 and 2009," International Journal of Infectious Diseases, vol. 17, no. 4, pp. e259-e262, 2013.

[23] G. Zahariadis, S. S. Plitt, S. O’Brien, Q.-L. Yi, W. Fan, and J. K. Preiksaitis, "Prevalence and estimated incidence of bloodborne viral pathogen infection in organ and tissue donors from northern Alberta," American Journal of Transplantation, vol. 7, no. 1, pp. 226-234, 2007.

[24] S. Raina, S. K. Raina, R. Kaul, and V. Sharma, "Seroprevalence of hepatitis $\mathrm{B}$, hepatitis $\mathrm{C}$, human immunodeficiency virus surface, and syphilis among blood donors: a 6-year report from a sentinel site in Western Himalayas, India," Indian Journal of Sexually Transmitted Diseases, vol. 36, no. 2, pp. 220-221, 2015. 
[25] A. Shrivastav, U. Bhavsar, A. Ramanuj, J. Joshi, A. Agnihotri, and O. Bodarya, "Seronegativity HBsAg, HCV and HIV among blood donors: a five year study," Muller Journal of Medical Sciences and Research, vol. 6, no. 2, pp. 142-146, 2015.

[26] C. J. Uneke, O. Ogbu, P. U. Inyama, G. I. Anyanwu, M. O. Njoku, and J. H. Idoko, "Prevalence of hepatitis-B surface antigen among blood donors and human immunodeficiency virusinfected patients in Jos, Nigeria," Memorias do Instituto Oswaldo Cruz, vol. 100, no. 1, pp. 13-16, 2005.

[27] A. B. Olokoba, S. K. Tidi, F. K. Salawu et al., "Human immunodeficiency virus infection in voluntary blood donors in NorthEastern Nigeria," American Journal of Scientific and Industrial Research, vol. 1, no. 3, pp. 435-438, 2010.

[28] R. N. Makroo, V. Hegde, M. Chowdhry, A. Bhatia, and N. L. Rosamma, "Seroprevalence of infectious markers \& their trends in blood donors in a hospital based blood bank in north India," Indian Journal of Medical Research, vol. 142, pp. 317-322, 2015.

[29] HIV/AIDS Estimates and Projections in Ethiopia, 2011-2016, National Aids Resource Center, http://www.etharc.org/index .php/resources/healthstat/hivaids-estimates-and-projections-inethiopia-2011-2016.

[30] Federal Ministry of Health/National HIV/AIDS Prevention and Control Office, "AIDS in Ethiopia," Sixth Report, Federal Ministry of Health/National HIV/AIDS Prevention and Control Office, 2011.

[31] A. A. Adjei, W. Kudzi, H. Armah, T. Adiku, A. G. Baidoe Amoah, and J. Ansah, "Prevalence of antibodies to syphilis among blood donors in Accra, Ghana," Japanese Journal of Infectious Diseases, vol. 56, no. 4, pp. 165-167, 2003.

[32] W.-C. Li, Y.-Y. Lee, I.-C. Chen, S.-H. Wang, C.-T. Hsiao, and S.S. Loke, "Age and gender differences in the relationship between hepatitis C infection and all stages of Chronic kidney disease," Journal of viral hepatitis, vol. 21, no. 10, pp. 706-715, 2014.

[33] W.-C. Li, Y.-Y. Lee, I.-C. Chen, C. Sun, F.-H. Chiu, and C.-H. Chuang, "Association between the hepatitis $\mathrm{B}$ and $\mathrm{C}$ viruses and metabolic diseases in patients stratified by age," Liver International, vol. 33, no. 8, pp. 1194-1202, 2013. 


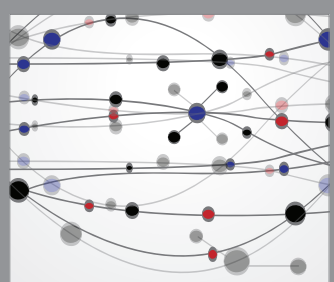

The Scientific World Journal
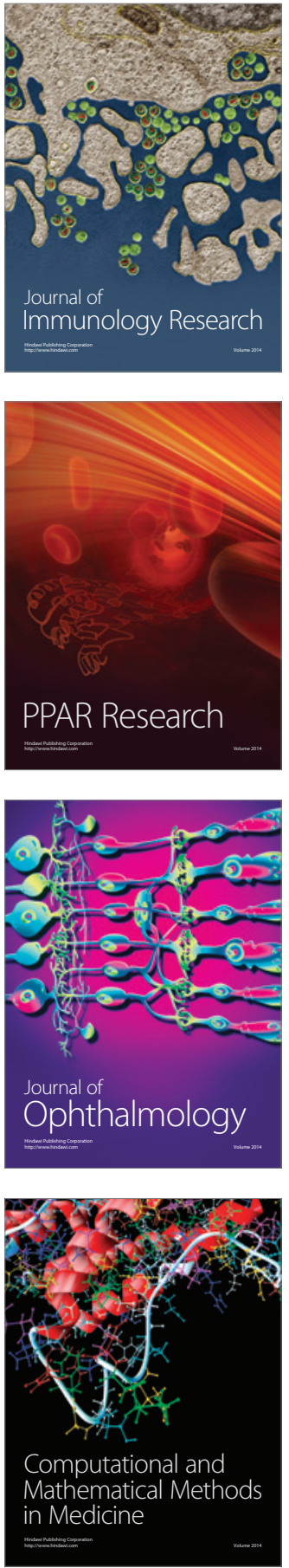

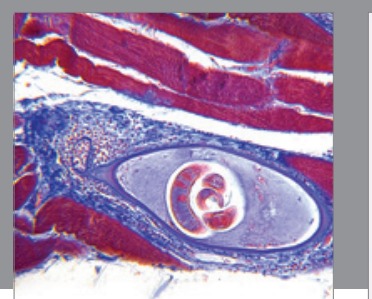

Gastroenterology Research and Practice

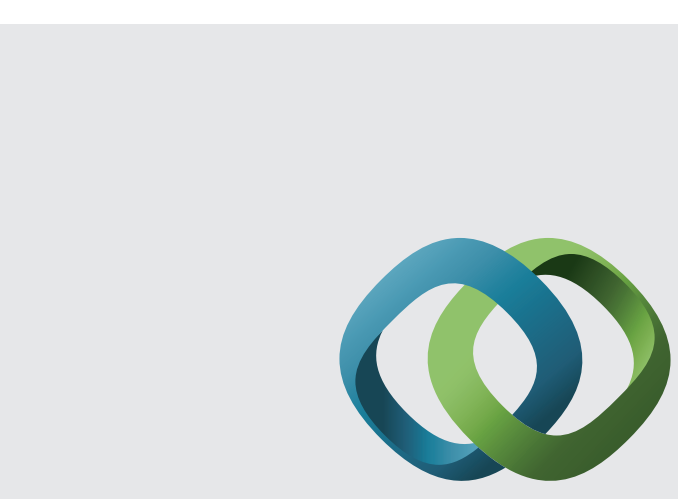

\section{Hindawi}

Submit your manuscripts at

http://www.hindawi.com
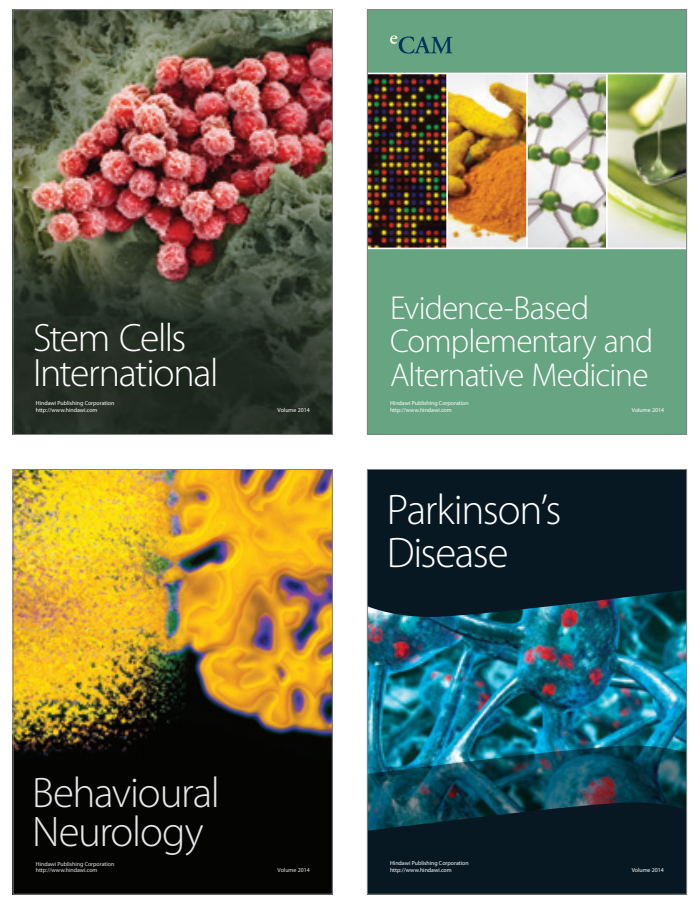
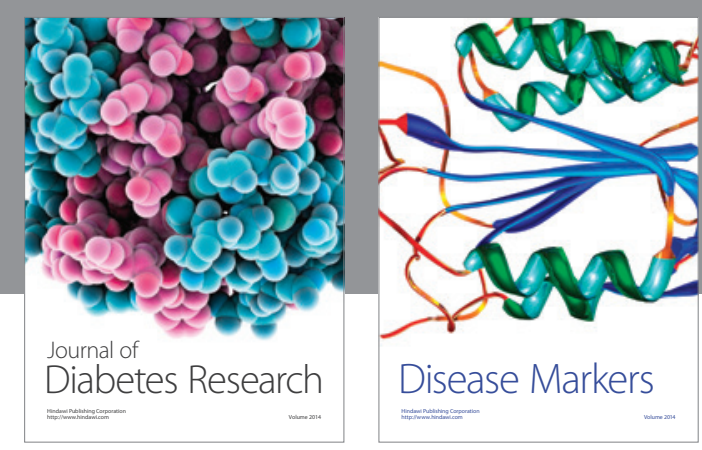

Disease Markers
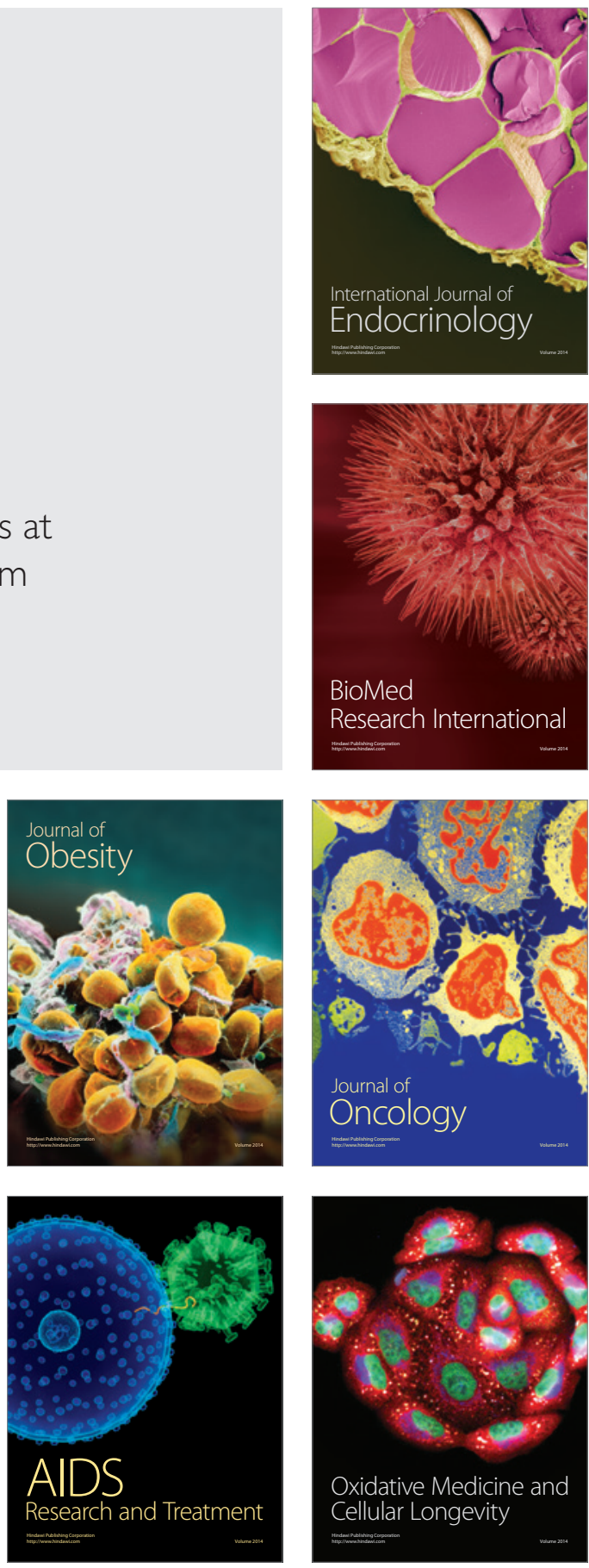